\title{
Desrazão, tragédia e experiência traumática brasileira em Qorpo Santo
}

\section{Resumo}

Ivan Delmanto ${ }^{1}$

O texto trata da formação da dramaturgia brasileira por meio de uma experiência social subjetiva e trágica encontrada na peça de Qorpo Santo Hoje sou um; e amanhã outro.

Palavras-chave: dramaturgia brasileira; subjetividade; tragédia.

\section{Abstract}

The text deals with the formation of dramaturgy brazilian by means of a social experience subjective and tragic found in play of Qorpo Santo Hoje sou um; e amanhã outro .

Keywords: brazilian dramaturgy; subjectivity; tragedy.

\section{Máquina dialética da desrazão}

Fredric Jameson define o romance, em O inconsciente político, como um processo mais do que como uma forma: um conjunto específico, quase que totalmente interminável, "de operações e procedimentos programáticos", em vez de um objeto acabado cuja estrutura imóvel poderia ser contemplada. Tal processo em que se constitui o romance o tornaria um ideologema narrativo cuja forma externa, "secretada como uma concha ou um exoesqueleto" continuaria a emitir sua mensagem mesmo depois da extinção do hospedeiro:

Nesse sentido, o romance desempenha um papel significativo no que poderia muito bem ser chamado de revolução cultural propriamente burguesa aquele imenso processo de transformações por meio do qual populações cujos costumes eram estabelecidos por outros modos de produção, agora arcaicos, são efetivamente reprogramadas para a vida e para o trabalho no novo mundo do capitalismo de mercado. ${ }^{2}$

\footnotetext{
1 Ivan Delmanto é diretor teatral, dramaturgo e educador. Bacharel em direção teatral pela ECA - USP é também mestre em Teoria Literária e Literatura Comparada na FFLCH USP. É doutorando PPGAC USP, na área de Teoria Teatral, onde desenvolve projeto de pesquisa sobre a formação do teatro brasileiro sob orientação da Profa. Dra. Maria Silvia Betti.
} 
O ideologema pode assim ser entendido como uma "formação anfíbia", cuja característica estrutural essencial pode ser descrita como sua possibilidade de se manifestar como pseudo-ideia - um sistema conceitual ou de crença, um valor abstrato, uma opinião ou um preconceito - ou como uma protonarrativa, uma fantasia de classe essencial com relação aos personagens coletivos que são as classes em oposição, fantasia que permite que uma aparente coerência interna e formal reprima o impensável, o que se coloca além dos limites de representação experimentados por determinada sociedade.

Poderíamos ler o drama burguês, descrito por Peter Szondi, como um ideologema, parte integrante da mesma constelação histórica que formou o romance. Durante a emergência do drama burguês, segundo Szondi:

O acento sobre o mérito patriótico dos comerciantes também é da maior relevância, bem como a equiparação com o nobre que se deriva daí [...] O comerciante age como instrumento da razão, na medida em que corrige sobre a terra a distribuição natural e, por assim dizer, irracional dos bens. [...] Levar à ordem a desordem natural constitui a tarefa do mercador. ${ }^{3}$

A partir de uma análise do drama O mercador de Londres, de Lillo, Szondi identifica como surgimento da tradição teatral burguesa a abolição da cláusula dos estados e, com a entrada do comerciante em cena, a afirmação dos ideais burgueses como função primordial da mimese teatral do período e de sua estrutura de sentimento. Os comerciantes do drama de Lillo não são imitados em sua "verdadeira" condição, mas apresentados como "deveriam ser", como portadores de uma missão social progressista. Assim, a forma dialógica do drama seria capaz de expressar, simultaneamente, um período histórico em que a racionalidade e o "raciocinar", como diz Hegel, constituem-se como critério para o estabelecimento dos pactos sociais, das relações capitalistas de poder e da verdade. O diálogo intersubjetivo do drama, caráter absoluto de sua forma, também baseada em um presente absoluto das ações, está baseado na emergência de um sujeito autônomo e centrado. Por outro lado, tal estrutura é capaz de revelar, se vista também em seu núcleo, uma ciranda geral de pantomimas em que o fetiche da mercadoria torna o flutuar do diálogo base da própria personalidade descentrada e fracionada do sujeito.

É possível identificar no Brasil um processo de (de)formação do drama bastante distinto. Podemos partir de uma afirmação de Décio de Almeida Prado que, no prefácio ao seu livro de críticas teatrais, Teatro em progresso, justifica a adoção do título da 
obra relacionando-o aos fragmentos do Finnegans Wake de James Joyce, publicados sob o título de work in progress, isto é, obra em andamento, ainda não concluída:

[...] não há dúvida de que toda obra de arte, todo gênero literário, jamais deixa de evoluir. Mas não é bem a isto ou apenas a isto que me refiro. A poesia e o romance brasileiro da fase propriamente modernista, por exemplo, alcançaram por vezes plenamente os seus objetivos.[...] Foram aquilo que sua época esperava e desejava que fossem. [...] Ora, é essa plenitude, embora relativa, que buscaríamos em vão no moderno teatro brasileiro. Para todos os efeitos, ele permanece ainda work in progress. ${ }^{4}$

Cabe então a pergunta: passados mais de quarenta anos da afirmativa feita por Décio, - pode-se falar em formação da dramaturgia brasileira? Partindo da descoberta de nosso crítico teatral, parece-nos que o percurso histórico brasileiro não se ajusta ao processo formativo da dramaturgia europeia, já que por aqui seria possível identificar uma espécie de acúmulo e sedimentação de diversos estágios ou modos de produção em simultaneidade, a conviverem em contradição, de maneira a fazer do atraso das relações sociais base de sustentação para formas de sociabilidade mais modernas. Assim, o movimento a ser tratado seria constituído por uma formação de ruínas, por uma antiformação de caráter trágico: o impulso contraditório e dilacerante que reúne, a todo momento, realidades e universos contrários, arruinando-os após cada colisão.

A importação dos modelos de sociabilidade surgidos na Europa, assolada por um processo histórico também ele altamente contraditório e desigual, teria sido expressa, entre nós, por diversas formações sociais fraturadas, que poderiam ser reveladas por um conceito ampliado de tragédia. Seria possível identificar, nesse percurso histórico contraditório, diversas manifestações de certa dialética trágica que, não obstante sua diversidade, poderia caracterizar este processo de formação singular. Diante de um quadro atual no qual tudo indicaria ser impossível que "nossa sociedade venha a se reproduzir de maneira consistente"5, seguimos Roberto Schwarz quando se pergunta sobre a ideia de formação: "E se a parte da modernização que nos tocou for esta mesma dissociação agora em curso, fora e dentro de nós? E quem somos nós nesse processo?"6 Talvez possamos afirmar que essa ideia ou ideal esteja simplesmente reduzida à miragem. $\mathrm{O}$ andamento da história teria inviabilizado o projeto passado; visto hoje, o contraste entre anseios e resultados atestaria a ilusão da utopia formadora.

\footnotetext{
4 PRADO, 1964, p.XVII.

5 SCHWARZ, 1999, p. 56.

6 SCHWARZ, 1999, p. 57
} 
Segundo Peter Szondi, a tragédia seria definida pela figuração da contradição: no gênero trágico, a consciência da dualidade é a consciência da cisão. A consciência da dualidade insolúvel, sem síntese possível.

\begin{abstract}
O trágico é um modus, um modo determinado de aniquilamento iminente ou consumado, é justamente o modo dialético. É trágico apenas o declínio que ocorre a partir da unidade dos opostos, a partir da transformação de algo em seu oposto, a partir da autodivisão. Mas também só é trágico o declínio de algo que não pode declinar, algo cujo desaparecimento deixa uma ferida incurável. Pois a contradição trágica não pode ser superada em uma esfera de ordem superior - seja imanente ou transcendente. ${ }^{?}$
\end{abstract}

Tentaremos, ao partir desse conceito de tragédia, identificar certo processo de deformação histórica no Brasil. Para isso, podemos identificar em peças e autores brasileiros uma dissolução dos modelos originais europeus formando tecidos textuais dilacerados por contradições múltiplas e aparentemente insuperáveis. Testar o conceito de tragédia para ler tais experiências é uma tentativa de figurar o processo interno que estrutura as relações constitutivas de nossa nacionalidade, o nosso processo particular de constituição histórico social marcado pela "modernização conservadora", em que as heranças de país colonial, escravocrata e patriarcal jamais são superadas, ao contrário, são agravadas com a passagem do tempo.

O jogo das oposições seria capaz de impor à forma trágica um incessante movimento pendular - similar ao da antiformação brasileira - entre extremos que nunca encontram um momento de síntese. Certas figurações de nossa dramaturgia poderiam ser vistas como o testemunho de que a formação - a integração social e cultural modelada no centro do capitalismo, mas com lógica e dinamismo próprios - tal qual idealizada pelas utopias de modernização - arruinou-se, elaborando, ao mesmo tempo, uma espécie de antiformação, que sobrevive dessas ruínas. Essa espécie de falência social geraria também uma subjetividade falida, trágica, mas antidramática por excelência, para falarmos em termos teatrais, por não dar dimensão ao conceito de indivíduo. Seria trágica, por contraditória e dilacerada. Se o nome freudiano dos "saberes não sabidos" é o Inconsciente, o nome freudiano dos "não saberes não sabidos" é trauma - a intrusão violenta de qualquer coisa de radicalmente inesperado, qualquer coisa para que o sujeito não estava em absoluto preparado e que não pode integrar seja de que maneira for: o que permanece, nessa experiência subjetiva, não é o fantasma do trauma, mas o próprio trauma. Slavoj Zizek chamou esses sujeitos de pós-traumáticos, comparando-o às vítimas de Alzheimer e de outras lesões cerebrais:

7 SZONDI, 2004, p. 34 
Não há continuidade entre esse novo sujeito pós-traumático e a sua identidade anterior: depois do choque, é literalmente um outro sujeito que emerge. Os seus traços são bem conhecidos: ausência de investimento afetivo, indiferença e distâncias profundas - trata-se de um sujeito trágico que não está mais dentro do mundo. O sujeito vive a morte como uma forma de vida - a sua vida é pulsão de morte encarnada, uma vida desprovida de investimento erótico ${ }^{8}$.

Falar, no Brasil, em sujeitos pós-traumáticos é cometer uma imprecisão, uma vez que é precisamente a persistência do trauma que torna a sua situação catastrófica. Talvez devamos falar em um sujeito-em-trauma para definir essa subjetividade brasileira que teria características tão distintas do indivíduo burguês tradicional. Perguntamo-nos se é possível traçar, no plano de uma experiência social subjetiva brasileira, um percurso de trauma contínuo que segue em paralelo ao nosso processo histórico de formação às avessas. Tal esboço, a ser traçado, estaria preocupado em fixar as máscaras mortuárias das vítimas dessa experiência social, dos soterrados pelo descarrilamento contínuo da locomotiva de nossa história.

\section{Delírio trágico Esclarecido}

A dramaturgia de Qorpo Santo constitui um caso singular entre nós de importação do modelo dramático burguês. Considerado por boa parte da fortuna crítica como uma espécie de precursor do surrealismo, também constitui opinião hegemônica que Qorpo Santo, por outro lado, com os pés fincados no tectonismo deslizante do século XIX, provavelmente pretendeu imitar os moldes de Joaquim Manoel de Macedo e de José de Alencar, estes últimos, eles próprios inspirados pelos modelos franceses, sobretudo da "comédia realista", uma espécie de 'alta comédia' que não tinha como objetivo primeiro provocar o riso, mas descrever costumes e discutir questões de interesse social da burguesia europeia. A divisão de suas peças em atos, quadros e cenas comprovaria que Qorpo Santo estava preocupado em escrever peças "bem-feitas", dentro dos moldes tradicionais vigentes na época, tentando, certamente, seguir parâmetros que devia conhecer. ${ }^{9}$ Essa dialética entre uma forma (dramática) retirada das comédias de costumes europeias e um conteúdo onírico, aparentemente delirante, teria levado alguns dos seus comentadores a considerá-lo também um mau escritor:

Qorpo Santo incorre num erro muito comum de pessoas que não têm hábito de lidar diretamente com o palco, ou seja, não tem noção de tempo em

8 ZIZEK, 2011, p. 358-361

9 FRAGA, 1988, p. 58. 
teatro. A sua divisão em cenas, quadros e atos é absolutamente arbitrária, e poderíamos, inclusive, questionar essa própria divisão. ${ }^{10}$

Mais do que a divisão em cenas e atos, parece arbitrária aos comentadores de Qorpo Santo a utilização do modelo do drama burguês que serviria como uma espécie de camisa-de-força ao pleno desenvolvimento dos conteúdos oníricos ou expressionistas tratados pelo dramaturgo. Daí a impressão de inabilidade na utilização da "carpintaria dramática" e de certa sensação de obra mal-acabada e desconjuntada, que a leitura crítica de Qorpo Santo geralmente pretendeu fixar. Vejamos uma cena da peça Hoje sou um; e amanhã outro para tentar compreender tal itinerário crítico:

MINISTRO - É cousa tão simples, quanto verdadeira: 1.a - Que os nossos corpos não são mais que os invólucros de espíritos, ora de uns, ora de outros; que o que hoje é Rei como V. M. ontem não passava de um criado, ou vassalo meu, mesmo porque senti em meu corpo o vosso espírito, e convenci-me, por esse fato, ser então eu o verdadeiro Rei, e vós o meu Ministro! ${ }^{11}$

Aparentemente, estamos diante do princípio da subjetividade descentrada, tal como descrito pela filosofia de David Hume. Mesmo sem conhecer o filósofo inglês, Qorpo Santo teria sido capaz de configurar a identidade como ficção de maneira muito próxima a de Hume. $\mathrm{O}$ dado novo no dramaturgo brasileiro estaria em situar o vagar das impressões que constituiriam a subjetividade no ar rarefeito de certa luta de classes, uma vez que o processo descrito pelo ministro foi capaz de transformá-lo, no dia anterior, de um funcionário burocrata na própria substância da majestade divina. $A$ revelação acima ocorre logo na cena inicial da peça e tem o poder de desestabilizar as crenças do rei, fazendo-o perdoar, no ato seguinte, dois suspeitos de uma conspiração armada para derrubá-lo do poder:

O REI - [...]Estais portanto servida, Senhora, em vosso pedido; mesmo que o não fizésseis, a conversação que acabo de ter com um dos nossos mais distintos políticos, e atualmente na primeira pasta do Governo, seria bastante para perdoar a esses, de quem tive denúncia de que conspiram contra o nosso Governo! ${ }^{12}$

Assim, antecipando-se ao pedido de clemência que seria realizado pela Rainha, o Rei perdoa os possíveis conspiradores baseando-se na revelação, trazida pelo Ministro, acerca da instabilidade da subjetividade. Estaríamos diante da figuração de uma experiência subjetiva brasileira, marcada pelo fluxo constante de identidades, característica de uma sociedade "formada por múltiplas culturas e etnias"? O reconhecimento dessa experiência teria gerado

10 FRAGA, 1988, p. 58

11 LEÃO, 2000, p. 184.

12 LEÃO, 2000, p. 187 
a ação do rei. Esta primeira leitura constituiria o nosso exoesqueleto da peça, o ideologema que a recobre impedindo-nos de enxergar o que o tecido mais profundo esconde.

Na perspectiva de Zizek, toda formação discursiva deve ser entendida em relação com aquilo que não pode acomodar dentro de seus próprios termos discursivos ou simbólicos. Este "exterior traumático" chega a ser a ameaça que motiva e, eventualmente serve de obstáculo, à ambição linguística de obter a inteligibilidade. A ininteligibilidade de Qorpo Santo, se seguirmos esse caminho, talvez esteja relacionada não a uma falta de habilidade do dramaturgo em dividir seu material corretamente entre atos e cenas, ou a qualquer outro pecado de mau dramaturgo, mas sim a um núcleo traumático da própria experiência histórica e subjetiva nacional.

Se retomarmos as formulações de Louis Althusser, a ideia de que toda formação ideológica se constitui através e contra um antagonismo constitutivo e, por consequência, deve ser entendida como um esforço por encobrir ou suturar uma série de relações conflituosas, talvez seja possível ler o drama de Qorpo Santo para além do seu exoesqueleto. Mas como essa sutura ideológica nunca seria completa, quer dizer, posto que nunca pudesse se estabelecer como um conjunto necessário ou geral, transparente, de conexões, estaria sempre marcada pela incapacidade de exercer uma determinação completa, por uma contingência constitutiva, que emerge dentro do campo ideológico como sua instabilidade permanente (e promissora). Seguiremos a promessa de tentar decifrar tal experiência traumática sem a pretensão de fornecer uma interpretação una e totalizadora do texto de Qorpo Santo, mas como possibilidade de lermos, por entre as frestas e fissuras da peça, traços de uma determinada experiência histórica subjetiva brasileira, o que nos distanciaria, no plano da formação de nossa dramaturgia, dos modelos europeus.

Após a revelação do Ministro, o Rei, encantado, deseja saber quem foi o sábio a formular tal teoria da identidade ficcional e pede um retrato do autor, para ser colocado em destaque na Corte:

O REI - Poderíamos obter um retrato desse ente a meu ver tão grande ou maior que o próprio Jesus Cristo!?

MINISTRO - Eu não possuo algum; mas pode se encomendar ao nosso Cônsul na cidade de Porto Alegre, capital da Província de São Pedro do Sul, em que tem habitado, e creio que ainda vive. [...] (Chega-se a uma mesa, pega em uma pena e papel, e escreve:)"Sr. Cônsul de... De ordem de Nosso Monarca, tenho a determinar a V. Sa. que no primeiro correio envie a esta Corte um retrato do Dr. Q... S..., do maior tamanho, e mais perfeito que houver. Sendo indiferente o preço. O Primeiro Ministro DOUTOR SÁ E BRITO" Corte de..., maio 9 de $1866^{13}$.

13 LEÃO, 2000, p. 187 
A data mencionada na carta a ser enviada pelo Ministro, 9 de maio de 1866, é geralmente atribuída na fortuna crítica do dramaturgo como o dia em que a peça estaria sendo escrita. Os dados geográficos, Rio Grande do Sul e Porto Alegre, remeteriam à biografia do próprio Qorpo Santo que assim pode ser visto como o sábio, tão importante quanto Jesus Cristo, citado na conversa entre o rei e seu ministro. É possível interpretar a peça como manifestação das idiossincrasias biográficas de Qorpo Santo; dessa forma poderíamos encarar a flutuação subjetiva mencionada como retrato do próprio autor, em um outro procedimento a antecipar as confissões surrealistas ou, indo mais além, até mesmo a escrita performativa dos textos pós-dramáticos mais contemporâneos. Tal interpretação parece justificável, mas ainda estamos tateando o exoesqueleto do ideologema, distantes de uma experiência traumática capaz de abrir uma lacuna na linguagem, à espera de decifração.

Sigamos com a leitura da peça. Mais adiante, o país é atacado por tropas inimigas. Em um procedimento épico notável, digno das narrações de batalhas que nos fazem os personagens de Shakespeare, Qorpo Santo narra, por meio da rainha, a violenta e brutal batalha que transcorre fora do palácio, na praia, durante o desembarque inimigo:

\footnotetext{
A RAINHA - (apita; um soldado da guarda imperial ou real responde com um toque de cometa; ela torna a apitar; ele fala.) Corre; voa onde está o Rei, e dize-Lhe que desembarcaram tropas inimigas na península(...) Como saltam cabeças, pernas, braços pelos ares! Que carnificina horrível se observa!? Como se matam; como se destroem entes humanos! ${ }^{14}$
}

Retomemos os dados de nossa investigação: estamos no ano de 1866, no Rio Grande do Sul, em uma localidade próxima a Porto Alegre. Há um rei que participa de uma guerra sangrenta. Parece-me possível conjecturar se estamos diante de uma chave alegórica que perdeu seu sentido ao longo do tempo, por meio da sutura ideológica, mas que pode ser agora recuperada se contemplarmos a Guerra do Paraguai.

O Rio Grande do Sul dos séculos XVIII e XIX é tradicionalmente recordado como supridor de tropas e meios logísticos para os embates entre o império português e o império espanhol, e posteriormente, para o império brasileiro em suas intervenções nas repúblicas do Prata. A província rio grandense teve seu território invadido pelos paraguaios no ano de 1865. A cidade de Uruguaiana foi tomada pelas tropas paraguaias comandadas pelo general Estigarribia e recuperada após um cerco pelas tropas da Tríplice Aliança. Nesse episódio, o imperador D. Pedro II esteve presente no

14 LEÃO, 2000, p. 191. 
campo de batalha, acompanhado de seu genro, o Conde D'Eu. O Conde escreveu um diário de sua viagem, intitulado “Viagem militar ao Rio Grande do Sul”, importante obra testemunhal que fornece elementos para uma análise da experiência traumática do período estudado:

Os paraguaios, saindo do seu país, atravessaram, sem disparar um tiro, a província argentina de Corrientes; em seguida passaram Uruguai na parte superior do seu curso e penetraram na província brasileira do Rio Grande do Sul, apoderando-se das vilas de São Borja e Itaqui ${ }^{15}$

Talvez seja possível ler na peça de Qorpo Santo, em uma primeira camada de sentido, uma figuração quase realista da Guerra do Paraguai. Mas não estamos diante do código realista do drama burguês, somente. O tempo todo, a narrativa linear da peça, quase transparente quando confrontamos as cenas com os dados reais da experiência histórica traumática da guerra, é interrompida por ações injustificadas, dando à peça o encadeamento lógico da desrazão e do pesadelo. Além da teoria sobre a subjetividade, que tão rapidamente faz o Rei mudar completamente sua conduta, vemos a batalha sangrenta ser interrompida para que o monarca troque de roupa:

O REI - (entrando banhado em sangue e suores; para a Rainha) Senhora, mandai-me vir outro fardamento limpo para mudar.

RAINHA - Entremos nesta câmara. (Entram, e passados alguns minutos, ele se apresenta com nova farda, calças, etc.) Adeus! Volto ao combate; e jurovos que antes de pôr-se o sol, não ficará um soldado inimigo em território nosso. (Parte. $)^{16}$

A atitude injustificada do Rei interrompe a unidade do drama burguês, gerando uma ação impossível de ser justificada dentro dos critérios tradicionais de construção do bom personagem dramático. Como interpretar essa lógica desarazoada presente na peça? Talvez possamos recolher alguns escombros da experiência sangrenta da Grande Guerra.

Em Qorpo Santo a ausência de sentido da Guerra parece ser corroborada pela ausência de sentido da própria forma do drama, esburacada pelas "atitudes injustificadas" de seus personagens. Haveria, no procedimento delirante de Qorpo Santo, uma maneira de representar o trauma da guerra vivido pela experiência social subjetiva de suas vítimas. Vejamos o final da peça brasileira:

O REI - (Senta-se; pega a pena, e escreve:) "Meus muito amados súditos e Governadores das diversas Províncias do meu importante Reino! Participovos, e sabei que quase inesperadamente fui surpreendido por numerosos traidores, ladrões e assassinos, mas que em um dia, hoje cercado dos meus generais e dos mais valentes, denodados soldados, obtive o mais completo triunfo sobre eles. (...)E conservai-vos, como sempre, no desempenho tão

15 ORLEANS, 1936, p. 27. 16 LEÃO, 2000, p. 193. 
honroso, quão importante do Governo que vos conferiu O vosso Rei Q... s, m. - Palácio das Mercês, Abril 9 de 1866."

O REI E A RAINHA - (para o publico) Sempre a Lei, a Razão e a Justiça triunfam da perfídia, da traição e da maldade! ${ }^{17}$

O que chama atenção em primeiro lugar é o final reconciliado que a peça abriga. Após o banho de sangue, o reino estaria de novo higienizado, graças ao genocídio cometido pela aliança entre soldados e generais, elite e povo. Há um contraste violento entre as descrições brutais da guerra e esse final apaziguado e utópico, o que parece nos revelar que a continuidade da sociedade brasileira, alegorizada por aquele reino fictício, erigiu-se sobre os escombros da guerra. Tal interpretação - e não a leitura ideológica sobre a Guerra do Paraguai, que deposita nos sonhos expansionistas de um ditador, Solano Lopes, toda a responsabilidade pelos massacres - é obtida exatamente graças à lógica do delírio. O que interrompe o fluxo linear e hegemônico da história, fazendo abrir as feridas anteriormente suturadas, é o delírio. Se não tivéssemos acompanhado o Rei trocar de roupa durante a guerra, ou a Rainha discutir com suas damas sobre o horário do almoço, logo após a narração das atrocidades, seria possível não estranhar a reconciliação proposta pelo casal na última frase da peça. Mas por estarmos diante de uma estrutura dramática própria, que questiona os preceitos do drama burguês europeu transformando o que havia de llustração em barbárie, é possível identificar na experiência da Guerra do Paraguai um trauma suturado pela narrativa ideológica, coerente e racional. A desrazão não atua apenas como conteúdo da ação dos personagens, mas está presente na própria estrutura dramática da peça: a divisão das cenas e dos atos é injustificada tanto quanto as interrupções ou a psicologia dos personagens. Estamos diante não de um mau dramaturgo, mas de uma peça que soube plasmar, por meio da desrazão, a convivência contraditória, no Brasil, entre discurso liberal e prática genocida.

Mas ainda há um detalhe fundamental. Vejamos como o Rei assina a sua participação oficial: “Q....S..." Qorpo Santo? O Rei torna-se, ao longo da peça, o próprio autor, que é também o filósofo que expôs sua doutrina no começo da trama. O processo de exposição da desrazão está completo com a flutuação final da identidade do próprio protagonista da peça. O que é possível ler nessa flutuação?

Estaríamos, ao ler a cena final da peça de Qorpo Santo, diante de um giro ainda mais desarrazoado e paradoxal: talvez não seja possível fazermos justiça à função ideológica e à função crítica da peça, a menos que queiramos aceitar a presença,

17 LEÃO, 2000, p. 193. 
nas crateras do texto, também de uma função mais positiva: daquilo que poderíamos chamar de seu potencial utópico e transcendente:

\footnotetext{
Pequena proposta metodológica para a dialética da história cultural .(...) É de importância decisiva aplicar novamente uma divisão a essa parte negativa, inicialmente excluída, de modo que a mudança de ângulo de visão ( mas não de critérios!) faça surgir novamente, nela também, um elemento positivo e diferente daquele anteriormente especificado. E assim por diante, ad infinitum, até que todo o passado seja recolhido no presente em uma apocastase (admissão de todas as almas no Paraíso) histórica ${ }^{18}$.
}

O conceito de apocastase, apresentado acima por Benjamin, é fundamental para compreendermos a feição traumática da experiência social subjetiva figurada na peça de Qorpo Santo. A transformação do Rei em Qorpo Santo é alegoria de um sonho de apocastase geral: nada mais paradisíaco do que se transformar em um homem "mais importante do que Jesus Cristo". No entanto, essa apocastase revela o seu contrário, seu processo de encobrimento do trauma e não de redenção.

Em Hoje sou um; e amanhã outro não estamos diante da subjetividade do drama burguês europeu. A razão e as razões burguesas expostas nos determinantes textuais do drama aqui se transformam em desrazão, em delírio, voando em círculos sobre o vazio de uma base social colonial que produz, como ideologia, uma autoimagem liberal e progressista. A utopia delirante do Rei e da Rainha, que acreditam poder apagar o rastro sangrento da guerra escrevendo uma carta, e a utopia real do Quilombo do Gran Chaco, que acreditou poder paralisar a guerra fugindo dela, são o pontos cegos que revelam o seu negativo: recolher a subjetividade brasileira ao Paraíso, fazer sua apocastase, é reconhecê-la por meio do seu sonho e do seu trauma.

A utopia funciona no Brasil exposto na peça de Qorpo Santo como delírio porque serve de ideal apaziguador para aquilo que não pode ser reconciliado. É como se o trauma crescesse graças à sua sutura: a utopia não pode ter aqui a pretensão de redenção porque serve como ideologema, tentando encobrir o horror do trauma coletivo. Nesse deslocamento entre utopia e realidade, ou na inversão de sinal da utopia, que transforma resistência em sutura, tal a magnitude do horror, talvez seja possível ler mais um traço - instável e provisório, é verdade - daquilo que tratamos aqui de experiência social subjetiva. A dramaturgia de Qorpo Santo pode nos revelar que tal subjetividade brasileira, acúmulo de escombros, armazenados nos túmulos dos soterrados de tal processo histórico, é mais do que instável ou mutante, é pura desrazão, funcionando na lógica do delírio quando procura recolher ao Paraíso a rocha cheia de sangue do Inferno.

18 BENJAMIN, 2007, P. 501. 


\section{Referências Bibliográficas}

JAMESON, Fredric. O Inconsciente político. São Paulo: Ática, 1992.

SZONDI, Peter. Teoria do drama burguês. São Paulo: Cosacnaify, 2004, p. 64.

DE ALMEIDA PRADO, Décio. Teatro em progresso: crítica teatral (1955-1964). São Paulo: Editora Perspectiva, 1964.

SCHWARZ, Roberto. Os sete fôlegos de um livro. In: Seqüências brasileiras: ensaios. São Paulo: Companhia das Letras, 1999, p.46-58.

SZONDI, Peter. Ensaio sobre o trágico. São Paulo: Zahar, 2004.

ZIZEK, Slavoj. Viver no fim dos tempos. Lisboa: Relógio d 'água, 2011.

FRAGA, Eudynir. Surrealismo ou absurdo?. São Paulo: Perspectiva, 1988.

LEÃO, José Joaquim de Campos. (Qorpo Santo). Hoje sou um; e amanhã outro. In: Teatro completo. São paulo: Iluminuras, 2000.

ORLEANS, Luis Filipe Maria Fernando Gastão de. Viagem militar ao Rio Grande do Sul. São Paulo: Cia. Editora Nacional, 1936.

BENJAMIN, Walter. As Passagens. São Paulo: EDUSP, 2007. 